\title{
RETRACTED ARTICLE: Ontology for distributed architecture of pedagogical warehouse in the field of machine learning
}

\author{
Adil Korchi ${ }^{1}$ (D) Najiba El Amrani El Idrissi ${ }^{1} \cdot$ Fayçal Messaoudi $^{2}$ • \\ Mohamed Dardor ${ }^{3}$
}

Received: 12 May 2020 / Accepted: 25 June 2020/Published online: 12 July 2020

(C) Springer Science+Business Media, LLC, part of Springer Nature 2020

The Editor-in-Chief has retracted this article [1] because it significantly overlaps with a previously published paper by Nawel et al. [2].

Adil Korchi disagrees with the retraction but has not explicitly stated whether he agrees to this retraction notice. The other authors did not respond to correspondence regarding this retraction.

\section{References}

1. Korchi, A., El Amrani El Idrissi, N., Messaoudi, F. et al. Ontology for distributed architecture of pedagogical warehouse in the field of machine learning. Educ Inf Technol (2020). https://doi. org/10.1007/s10639-020-10266-5.

2. Nawell Iles, Azeddine Chikh, Josiane Mothe. Architecture distribuée d'un entrepôt pédagogique. Revue de l'EPI (Enseignement Public et Informatique), EPI, 2008, pp.[en ligne]. https://hal-univ-tlse3.archivesouvertes.fr/edutice-00402496.

Supplementary Information The online version contains supplementary material available at https://doi. org/10.1007/s10639-020-10266-5.

Adil Korchi

adil.korchi@gmail.com

Najiba El Amrani El Idrissi

n.elamrani@usmba.ac.ma

Fayçal Messaoudi

faycal.messaoudi@usmba.ac.ma

Mohamed Dardor

mohamed.dardor@usmba.ac.ma

1 Laboratory of Signals, Systems and Components - Faculty of Sciences and Technics, University Sidi Mohamed Ben Abdellah, Fez, Morocco

2 National School of Business and Management, University Sidi Mohamed Ben Abdellah, Fez, Morocco

3 Faculty of Sciences, Dhar El Mehrez, University Sidi Mohamed Ben Abdellah, Fez, Morocco 